\title{
Experimental study on the key factors of low-loss threshing of high-moisture maize
}

\author{
Xiaolong Zhu ${ }^{1,2}$, Ruijuan $\mathrm{Chi}^{1,{ }^{2 *}}$, Yuefeng $\mathrm{Du}^{1,2}$, Jiahao Qin ${ }^{1,2}$, Zexin Xiong ${ }^{1,2}$, \\ Weitong Zhang ${ }^{1,2}$, Xiaoyu $\mathrm{Li}^{1,2}$ \\ (1. College of Engineering, China Agricultural University, Beijing 100083, China; \\ 2. Beijing Key Laboratory of Optimized Design for Modern Agricultural Equipment, China Agricultural University, Beijing 100083, China)
}

\begin{abstract}
The rates of maize breakage and entrainment loss are high in the harvest of high-moisture maize, which remains an issue with the development of agricultural mechanization. In order to reduce the maize breakage and entrainment loss rates, the correlations among key factors, such as the threshing cylinder speed, concave clearance and feeding rate, and the rates of breakage and entrainment loss during high-moisture maize harvesting were studied in this paper. A single-factor experiment was carried out using a single-longitudinal-axial flow maize harvester, and an orthogonal experiment was carried out using single- and double-longitudinal-axial flow maize harvesters with the Taguchi experimental design method. The single-factor experiment revealed that when the cylinder speed increased, the breakage rate of maize decreased first and then increased, while the entrainment loss rate decreased. The breakage rate of maize decreased as the concave clearance increased, while the entrainment loss rate decreased first and then increased. The optimum value of the concave clearance was positively correlated with the ear diameter of maize; Additionally, the minimum breakage rate of maize occurred when the feeding rate was at the rated value, and the entrainment loss rate increased as the feeding rate increased. The orthogonal experiments revealed that the importance of cylinder speed, feeding rate, concave clearance on the maize breakage and entrainment loss rates were in descending order. The optimum values of parameters for the single-longitudinal-axial flow maize harvester were $370 \mathrm{r} / \mathrm{min}$ cylinder speed, $40 \mathrm{~mm}$ concave clearance and $10 \mathrm{~kg} / \mathrm{s}$ feeding rate. The optimum values of parameters the double-longitudinal-axial flow maize harvester were $550 \mathrm{r} / \mathrm{min}$ cylinder speed, $35 \mathrm{~mm}$ concave clearance and $10 \mathrm{~kg} / \mathrm{s}$ feeding rate. The research can provide a reference for parameter configuration and control strategy for the longitudinal-axial flow maize harvester with high-moisture maize.
\end{abstract}

Keywords: high-moisture maize, maize harvester, parameter configuration, Taguchi experiment DOI: $10.25165 /$ j.ijabe.20201305.5653

Citation: Zhu X L, Chi R J, Du Y F, Qin J H, Xiong Z X, Zhang W T, et al. Experimental study on the key factors of low-loss threshing of high-moisture maize. Int J Agric \& Biol Eng, 2020; 13(5): 23-31.

\section{Introduction}

Maize is currently the world's highest-yielding food crop, occupying only less acreage than wheat and rice ${ }^{[1]}$. According to China's statistics bureau, in 2017, maize was the crop with the largest planted area in China, but there was less mechanized harvesting of maize than that of wheat and rice ${ }^{[2]}$. This gap exists mostly because maize is easily damaged during mechanized harvesting ${ }^{[3-7]}$. Maize harvesters can be divided into two types: direct maize threshing and the harvesting of maize ears ${ }^{[8]}$. Previous researches have shown that the moisture content of maize kernels affects their mechanical properties. The minimum grain damage during maize threshing occurs at moisture contents between $20 \%$ and $22 \%$. When the moisture content of maize

\section{Received date: 2020-01-07 Accepted date: 2020-05-21}

Biographies: Xiaolong $\mathbf{Z h u}, \mathrm{PhD}$ candidate, research interest: vehicle electronic control, Email: zxlcau@163.com; Yuefeng Du, PhD, Associate Professor, research interest: vehicle electronic control, Email: dyf@cau.edu.cn; Jiahao Qin, $\mathrm{PhD}$ candidate, research interest: tractor stability control, Email: qinjh@cau.edu.cn; Zexin Xiong, Master candidate, research interest: vehicle electronic control, Email: xiongzexin@yeah.com; Weitong Zhang, Master candidate, research interest: vehicle electronic control, Email: dfzhangweitong@163.com; Xiaoyu Li, PhD candidate, research interest: vehicle electronic control, Email: 1xy940724@163.com.

*Corresponding author: Ruijuan Chi, PhD, Associate Professor, research interest: vehicle electronic control. China Agricultural University, Haidian District, Beijing 100083, China. Tel: +86-10-62736730, Email: chiruijuan@ cau.edu.cn. kernels exceeds 28\%, they become soft and more easily damaged $^{[9,10]}$. That is, the greater the maize's moisture content, the more easily the kernels are broken ${ }^{[11-13]}$. In the United State and European countries, maize used for grain production is traditionally harvested when the moisture content is about 18\%-25\%; therefore, direct maize threshing has been the main harvesting method ${ }^{[14]}$. In recent years, China has also gradually adopts the direct maize-threshing harvesting method; however, most of the maize-growing areas in China, especially in the Huang-Huai-Hai Region, are planted with winter wheat and summer maize. The maize moisture content is generally high, ranging from $25 \%$ to $35 \%$ during the harvest ${ }^{[15-17]}$. To adapt to high-moisture maize during harvesting, the development of a low-damage threshing technology is urgently needed in China ${ }^{[18,19]}$.

The harvesting of maize kernels can be divided into three processes: ear picking, threshing and cleaning. The threshing process accounts for a large proportion of maize loss ${ }^{[20,21]}$. The mechanisms parameters directly relating to the threshing process are concave clearance and cylinder speed. Therefore, there is much research on these parameters. Petkevichius et al. ${ }^{[22]}$ studied the effects of feeding direction, moisture content, cylinder speed and concave clearance on the threshing loss of maize and analyzed the force in the threshing process of maize with different moisture contents. Mahmoud and Buchele ${ }^{[9]}$ studied the effects of force and feeding direction on mechanical damage to maize ears. $\mathrm{Xu}$ et al. ${ }^{[23,24]}$ established a force equation for grain and threshing 
elements in the contact process depending on the collision angle, and they designed a threshing and separating device with a transverse axial flow cylinder and a scheme for the cylinder and concave clearance. Qu et al. ${ }^{[25]}$ designed a test to determine the optimum speed range of maize harvester cylinders at different feed quantities.

The key evaluation indexes of the maize harvester during the threshing process are the rates of maize breakage and entrainment $\operatorname{loss}^{[26]}$. Factors other than the threshing element affect threshing performance, such as the moisture content and feeding rate. Di et al. ${ }^{[27]}$ designed an axial flow threshing cylinder composed of a rasp bar block and nail tooth, and studied the effects of threshing cylinder speed, concave clearance and concave obliquity on the maize breakage and unthreshed rates. Lin and $\mathrm{Gao}^{[28]}$ carried out performance experiments for a differential speed seed thresher and studied the effects of cylinder speed, feeding rate and seeds' moisture content on the seed breakage rate. Keller et al. ${ }^{[29]}$ analyzed the effects of threshing speed and moisture content on maize kernel damage. However, most of the previous studies were carried out under ideal conditions in the laboratory on low-moisture maize. There are few studies on the threshing process of high-moisture maize, and there is no research comparing the parameter configurations between single- and double-longitudinal-axial flow maize harvesters. The configuration of threshing parameters for high-moisture maize is still mainly dependent on manual operation, which is subjective and inexact. Therefore, it is of great practical significance to study the configuration of key parameters during the threshing process of high-moisture maize to reduce the loss.

To address these problems, in this paper, the threshing process of single- and double-longitudinal-axial flow maize harvesters were studied, and the effects of cylinder speed, concave clearance and feeding rate on the evaluation indexes, breakage and entrainment loss rates of maize kernels, were analyzed. The effects of single factor on the two evaluation indexes and the optimal configuration parameters of three factors on the two types of harvesters were studied. The results can be used as a reference for parameter configuration during the harvesting process of high-moisture content maize using a longitudinal-axial flow maize harvester.

\section{Experimental system and key control mechanisms}

\subsection{Experimental platform}

Two mainstream models of longitudinal-axial flow maize harvesters in China were selected as the experiment platforms. One is a single-longitudinal-axial flow maize harvester $(10 \mathrm{~kg} / \mathrm{s}$ rated feeding rate, 6-row cut width, $0-8 \mathrm{~km} / \mathrm{h}$ harvest speed and $630 \mathrm{~mm}$ cylinder diameter, 4YL-6(ZL2150), Yongmeng Machinery Co., Ltd, No. 6 Xingan Road, Baodi Jiuyuan industrial park, Tianjin) with a longitudinally arranged cylinder (Figure 1a); The other is a double-longitudinal-axial flow maize harvester $(10 \mathrm{~kg} / \mathrm{s}$ rated feeding rate, 8 -row cut width, $0-8 \mathrm{~km} / \mathrm{h}$ harvest speed and 480 mm cylinder diameter,4YZT-8, Xinjiang Mushen Machinery Co., Ltd, No. 661 South Economic and Technological Development Zones Road, Urumqi City) with two longitudinally arranged cylinder (Figure 1b). To make the experimental process easy and to ensure the accuracy of parameter adjustment during the experiment, the operating systems of the two harvesters were improved, and all the key mechanisms were controlled by electronic systems. The concave clearance and the cylinder speed were controlled by a keyboard, and the vehicle speed was controlled by a handle (Figure 1c). Additionally, all data was displayed on a screen (Figure 1d) during the experimental operation, which enhanced the human-computer interactions during the process.

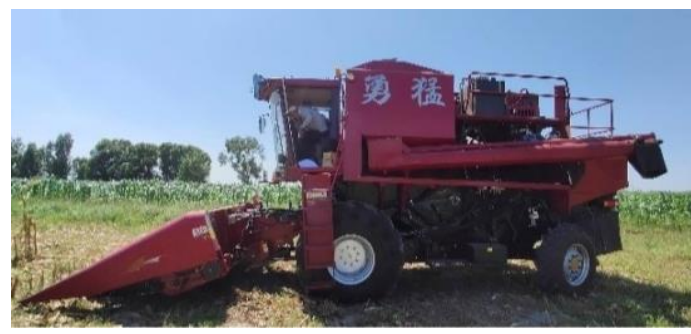

a. Single

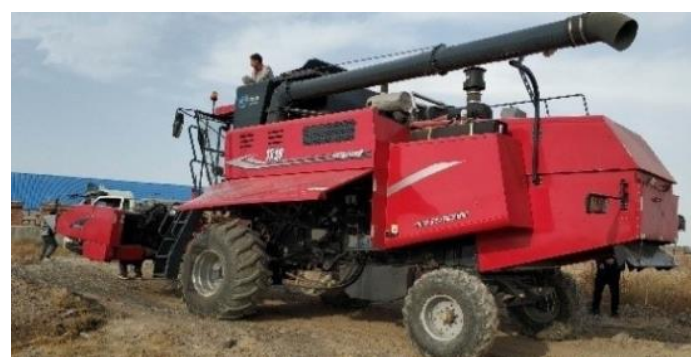

b. Double

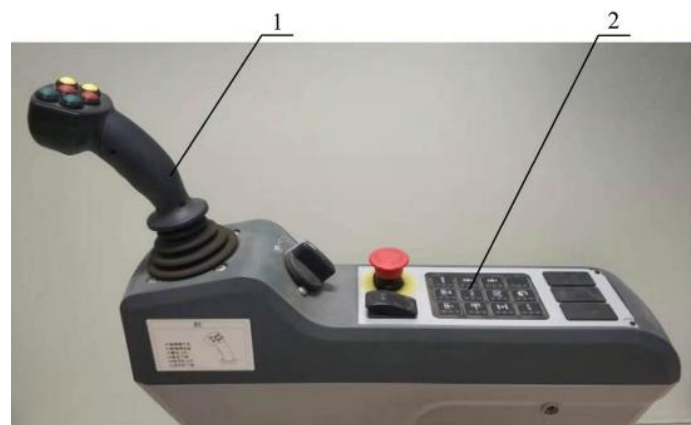

1. Handle 2. Keyboard

c. Control uni

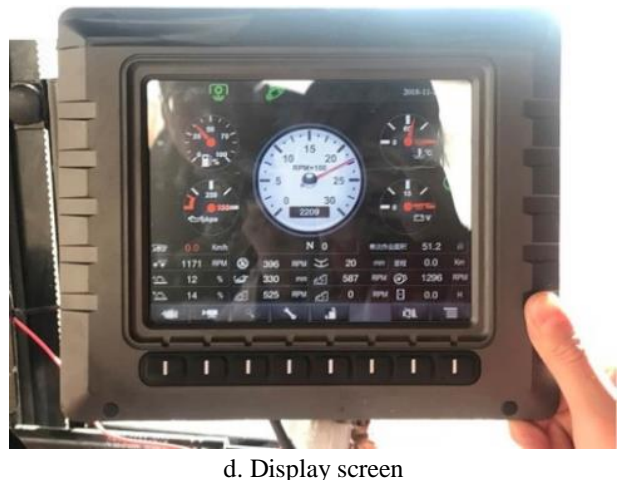

Figure 1 Longitudinal axial flow harvesters

\subsection{Data acquisition system}

In this paper, the data for the parameters of cylinder speed, concave clearance and vehicle speed was collected. Although changes in the parameters were observed in real-time on the display screen, to process the experimental data at a later stage a two-way controller area network (CAN) recorder (Figure 2) was used to collect and record the experimental data.

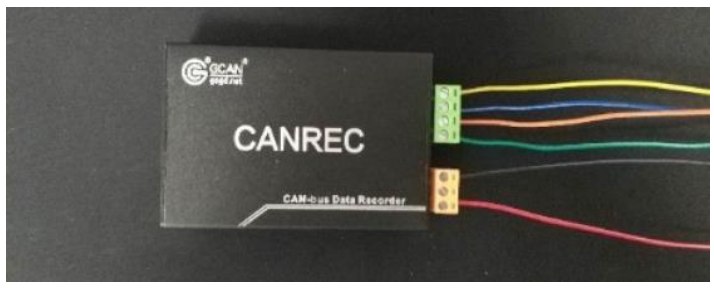

Figure 2 Controller area network recorder 


\subsection{Key control mechanism}

2.3.1 Mechanisms regulating the threshing cylinder speed

To study the effects of cylinder speed on the rates of maize breakage and entrainment loss, it is necessary to adjust the cylinder to the corresponding speed quickly and accurately in each experiment. Therefore, based on the original vehicle's cylinder speed regulating mechanism, an electronic control regulating mechanism for the cylinder speeds of the single- and double-longitudinal-axial flow harvesters was designed. The adjustment range for the cylinder speed is $0-1200 \mathrm{r} / \mathrm{min}$.

The speed of the cylinder was adjusted by changing the diameter of the continuously variable transmission (CVT) wheel. The control flow chart is shown in Figure 3. The speed adjustment process for the cylinder is as follows: The driver sends out a control command to change the cylinder speed through the keyboard, the electronic control unit (ECU) receives the signal and then controls the drive motor's rotation. The driving motor drives the CVT wheel to move axially through the transmission mechanism, realizing the step-less control of the cylinder speed. The cylinder speed sensor relays the change of cylinder speed to the ECU, and it is displayed on the screen, which improves the interactivity of the adjustment process.

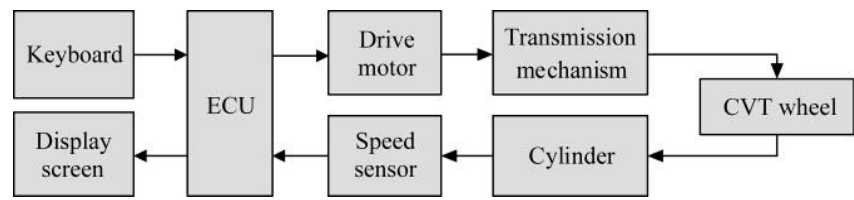

Figure 3 Flow chart of cylinder speed regulation

\subsubsection{Mechanisms regulating the concave clearance}

To make the adjusting of the concave clearance more convenient, the original mechanical adjustment mechanisms of the two models were improved to electronically controlled adjustment mechanisms. The control flow chart is shown in Figure 4. The ECU receives the command to change the concave clearance from the keyboard, and then controls the electric-driven putter to change the concave clearance, while the linear displacement sensor detects the current concave clearance in real-time. Using the display screen, this information is relayed to the driver to achieve an accurate adjustment in the concave clearance. The adjustment range for the concave clearance is $0-50 \mathrm{~mm}$.

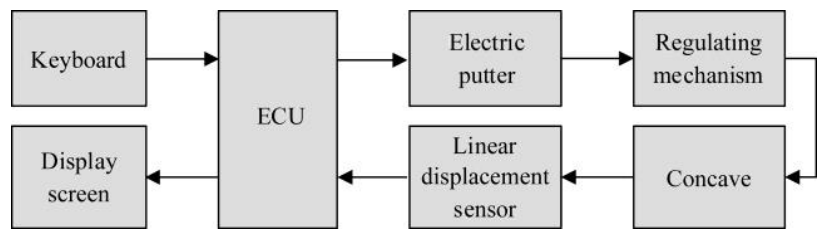

Figure 4 Flow chart of concave clearance regulation

\subsubsection{Regulation of feeding rate}

There are many factors that affect the feeding rate received by the maize harvester, such as vehicle speed, crop yield, crop moisture content and cut width. However, the only factor that affects the feeding rate when the same harvester is working in the same field is vehicle speed. Therefore, the vehicle speed was controlled to change the feeding rate. The vehicle-speed control system of a maize harvester contains a vehicle-speed sensor, ECU, control handle, electro-hydraulic proportional valve, walking variable pump and walking motor. The flow chart for vehicle speed control is shown in Figure 5. Using the handle, the driver sends a speed-change command to the ECU, which calculates and then controls the electro-hydraulic proportional valve to change the flow of the walking variable pump to alter the walking motor drive gearbox to regulate the speed. The speed adjustment range is 0 $8 \mathrm{~km} / \mathrm{h}$ during harvesting. The vehicle speed sensor detects the current speed in real-time, and the speed information is displayed on the screen.

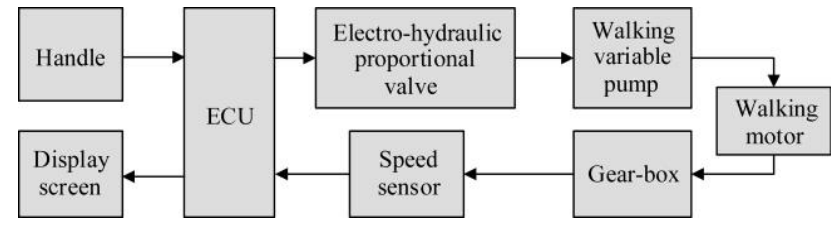

Figure 5 Flow chart of vehicle-speed control

\section{Experimental program and related calculations}

\subsection{Experimental program}

The experiment was carried out in accordance with the requirements of the relating standard rules $^{[30]}$. Before the experiment, the field was divided into three areas, a $20 \mathrm{~m}$ measuring area, a $20 \mathrm{~m}$ stable area and a $10 \mathrm{~m}$ parking area, as shown in Figure 6. Each area was marked with posts. During the experiment, the harvester first stabilized the working parameters in the stable area, and then entered the measuring area to harvest maize. When the harvester entered the measuring area, the plastic cloth was used to catch the bract discharge from the outlet and to collect loss of entrapped grains. After each group of experiments was completed, the maize kernel samples were collected from the pre-arranged collecting boxes in the granary.

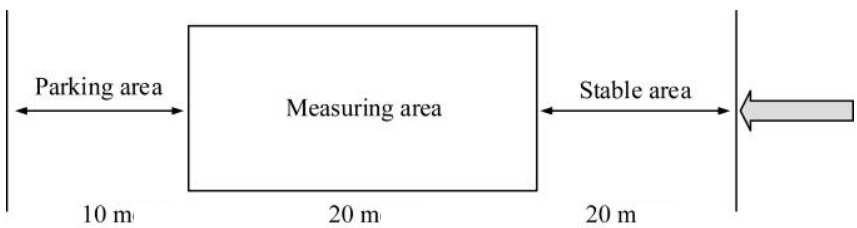

Figure 6 Diagram of the experimental area

\subsection{Feeding rate calculation}

The feeding rate during the experimental process was mainly regulated by vehicle speed. The maize ear samples were collected in accordance with the requirements of the relating standard rules $^{[31]}$. In this experiment, a sampling area of $4 \mathrm{~m}^{2}$ was selected randomly in the measuring area, and the maize ears were sampled randomly using the five-point method, counted and weighed. Using Equation (1), the corresponding vehicle speeds when the feeding rate was $8 \mathrm{~kg} / \mathrm{s}, 10 \mathrm{~kg} / \mathrm{s}$ and $12 \mathrm{~kg} / \mathrm{s}$ were calculated.

$$
V=\frac{20000 Q \cdot S}{G \cdot S_{Z}}
$$

where, $V$ is vehicle speed, $\mathrm{m} / \mathrm{s} ; Q$ is the feeding rate, $\mathrm{kg} / \mathrm{s} ; S$ is the number of sampled maize ears in the measuring area; $G$ is the weight of $S$, g; and $S_{z}$ is the total number of ears in the sampling area.

\subsection{Breakage rate of maize kernel calculation}

In accordance with the requirements of the relating standard rules $^{[32]}$, during each experiment, no less than $2000 \mathrm{~g}$ of maize samples were collected in the measuring area, and the broken rate of maize was calculated according to Equation (2), as follows:

$$
Z_{S}=\frac{W_{s}}{W_{i}} \times 100 \%
$$

where, $Z_{s}$ is the breakage rate of maize, $\% ; W_{s}$ is the weight of broken maize, $\mathrm{g}$; and $W$ is the total weight of the samples, $\mathrm{g}$. 


\subsection{Calculation of the entrainment loss rate for maize}

In accordance with the standard requirements of the relating standard rules ${ }^{[32]}$, for each experiment in the measuring area, all the discharged bract leaves from the outlet were collected and weighed the maize kernels from that, and the entrainment loss rate was calculated according to using Equation (3), as follows:

$$
S_{b}=\frac{W_{b}}{W_{z}} \times 100 \%
$$

where, $S_{b}$ is the rate of entrainment loss, $\%$; $W_{b}$ is the weight of discharged maize from the outlet of measuring area, $\mathrm{g}$; and $W_{z}$ is the total weight of the maize of measuring area, $g$.

\section{Experimental process}

The experiments were carried out on a single- and a double-longitudinal-axial flow maize harvester, respectively. The single-factor experiment was carried out to study the effects of cylinder speed, concave clearance and feeding rate on the rates of maize breakage and entrainment loss. The interactions among the three factors were considered in the orthogonal experiment. The optimal values of the parameters of three factors and the importance of the three factors on the maize breakage and entrainment loss rates were determined.

\subsection{Experimental study on a single-longitudinal-axial flow} maize harvester

The experiment of single-longitudinal-axial flow maize harvester was carried out in Tianjin, Baodi District, China $\left(117.3103^{\circ} \mathrm{E}, 39.71761^{\circ} \mathrm{N}\right)$. The experimental platform was a self-propelled single-longitudinal-axial flow maize harvester. Before the experiment, the moisture content of the maize was determined to be $31 \%$ using a portable grain moisture meter (PM-8188-A, KETT, Japan, 155 Xinyuan road, anting town, Jiading District, Shanghai), confirming that it was high-moisture maize. The experiments were carried out in two fields, and their basic information was shown in Tables 1 and 2 .

The cylinder speed and the concave clearance were adjusted using the keyboard. The feeding rate was controlled by the vehicle speed and could be calculated using Equation (1). The vehicle speed and feeding rate are shown in Table 3.

Table 1 Basic maize parameters in Field 1

\begin{tabular}{lc}
\multicolumn{1}{c}{ Parameters } & Value \\
\hline Average ear length/mm & 196 \\
Average large end diameter/mm & 63.2 \\
Average small end diameter/mm & 46.5 \\
Average ear weight (with bract leaves)/g & $337 / 445$ \\
Moisture content of maize/\% & 31 \\
Average number of plants in measuring area & 296 \\
\hline
\end{tabular}

Table 2 Basic maize parameters in Field 2

\begin{tabular}{lc}
\hline \multicolumn{1}{c}{ Parameters } & Value \\
\hline Average ear length/mm & 146 \\
Average large end diameter/mm & 51.3 \\
Average small end diameter/mm & 44.7 \\
Average ear weight (with bract leaves)/g & 387 \\
Moisture content of maize/\% & 27 \\
Average number of plants in measuring area & 283 \\
\hline
\end{tabular}

Table 3 Vehicle speed and feeding rate

\begin{tabular}{|c|c|c|c|}
\hline \multicolumn{3}{|c|}{ Vehicle speed $/ \mathrm{km} \cdot \mathrm{h}^{-1}$} & \multirow{3}{*}{$\begin{array}{l}\text { Feeding rate } \\
/ \mathrm{kg} \cdot \mathrm{s}^{-1}\end{array}$} \\
\hline \multicolumn{2}{|c|}{ Single longitudinal } & \multirow{2}{*}{$\begin{array}{c}\text { Double longitudinal } \\
\text { Field } 3\end{array}$} & \\
\hline Field 1 & Field 2 & & \\
\hline 4.37 & 5.26 & 3 & 8 \\
\hline 5.47 & 6.57 & 3.78 & 10 \\
\hline 6.56 & 7.89 & 4.54 & 12 \\
\hline
\end{tabular}

After each experiment, the samples were bagged and labelled, and the breakage and the entrainment loss rates were calculated using Equation (2) and Equation (3), respectively. The experimental diagram and samples are shown in Figures 7a-7e. The broken maize types are shown in Figure $7 \mathrm{f}$ which include broken maize kernels, skin damage and surface cracking.

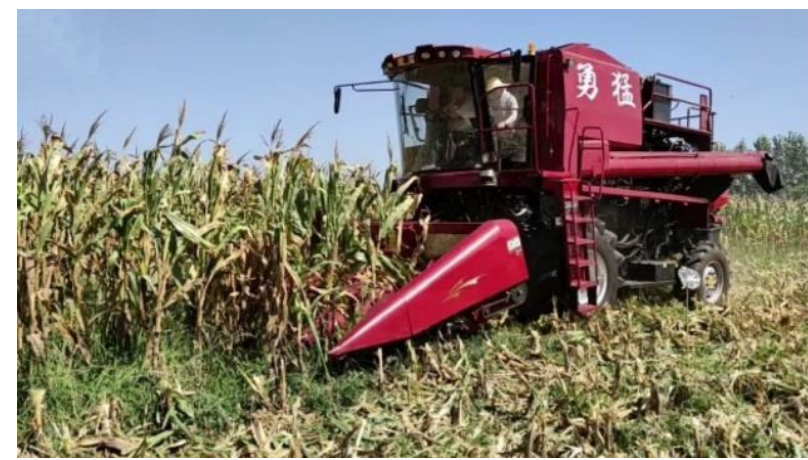

a. Field operation

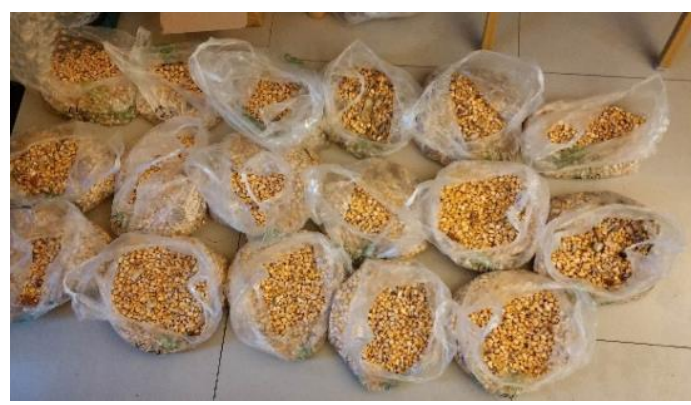

d. Granary samples

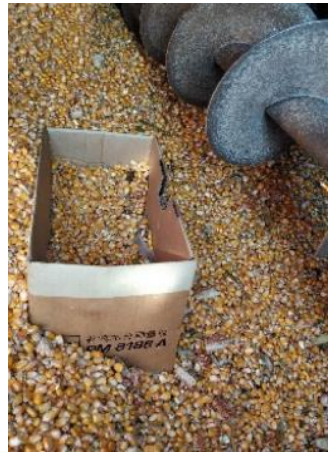

b. Sampling at the granary

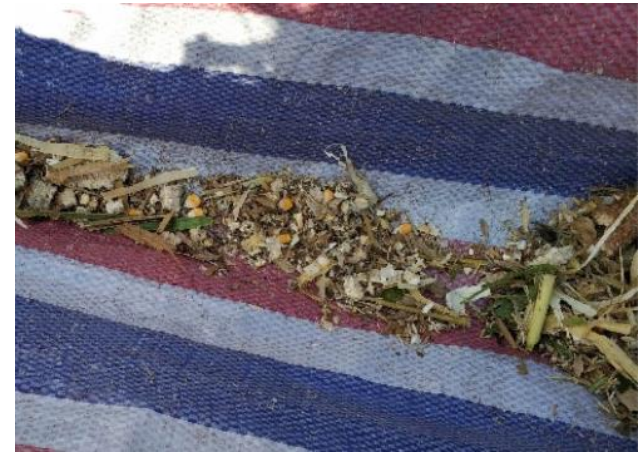

c. Sampling of bract leaves from the outlet

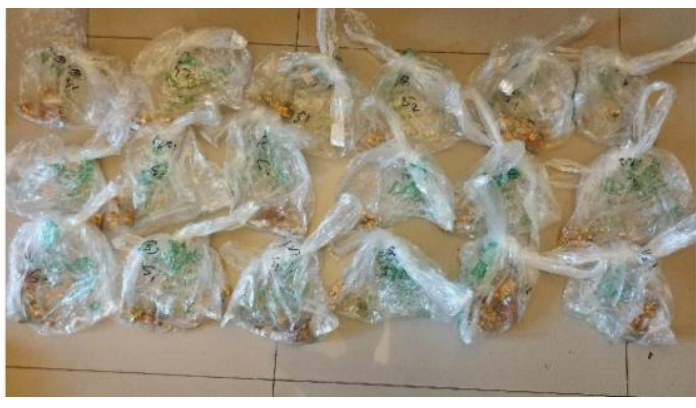

e. Bract leaf samples

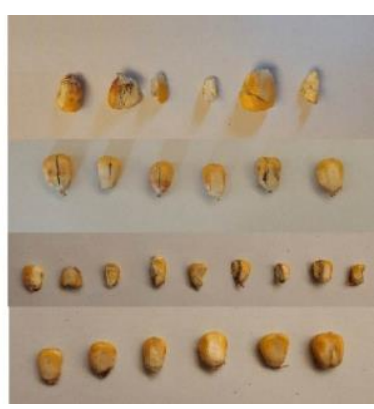

f. Maize breakage types

Figure 7 Harvesting process of single-longitudinal-axial flow maize harvester 


\subsection{Experimental study on a double-longitudinal-axial flow maize harvester}

The experiment of double-longitudinal-axial flow maize harvester was carried out in Junhu Farm, Xinjiang, China $\left(87.308221^{\circ} \mathrm{E}, 44.011184^{\circ} \mathrm{N}\right)$. The experimental machine was a self-propelled double-longitudinal-axial flow maize harvester. Before the experiment, the moisture content of the maize was determined to be $30 \%$, confirming that it was high-moisture maize. The basic information of the field is shown in Table 4 .

Table 4 Basic maize parameters in Field 3

\begin{tabular}{lc}
\multicolumn{1}{c}{ Parameters } & Value \\
\hline Average ear length/mm & 157 \\
Average large end diameter/mm & 54.3 \\
Average small end diameter/mm & 44.2 \\
Average ear weight (with bract leaves)/g & 403 \\
Moisture content of maize/\% & 30 \\
Average number of plants in measuring area & 472 \\
\hline
\end{tabular}

Cylinder speed and concave clearance were controlled using the handle and keypad settings, respectively. The feeding rate was corresponded to the speed, as shown in Table 3. Part of the experiment diagram is shown in Figure 8.

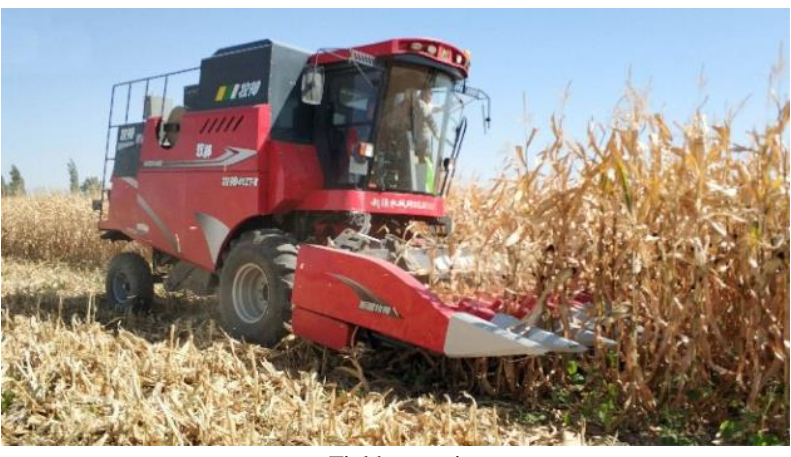

a. Field operation

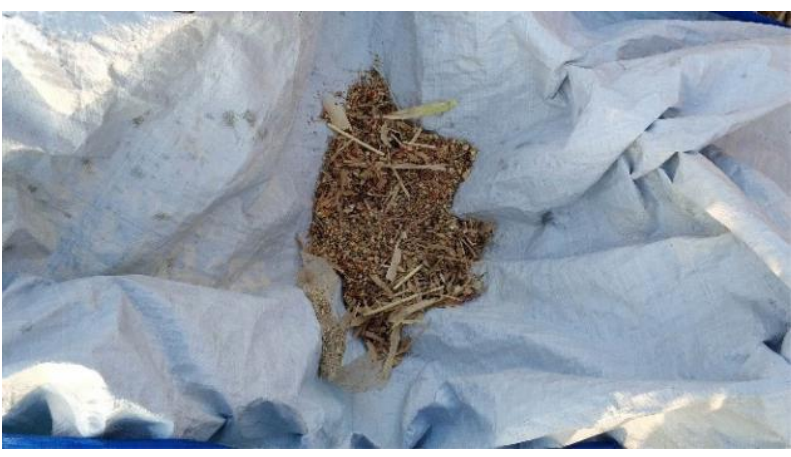

b. Sampling of bract leaves from the outlet

Figure 8 Harvesting process of double-longitudinal-axial flow maize harvester

\section{Results and discussion}

\subsection{Single-factor experiments}

The single-factor experiments were carried out on a single-longitudinal-axial flow maize harvester. During the experiment, other harvester parameters were constant, except the cylinder speed, concave clearance and feeding rate. Each set of experiments was repeated three times.

5.1.1 Effects of cylinder speed on the breakage and entrainment loss rates of maize

In Field 1, the single-factor cylinder speed experiment was carried out. The concave clearance was $35 \mathrm{~mm}$, the feeding rate was $10 \mathrm{~kg} / \mathrm{s}$, and the cylinder speed varied from $300 \mathrm{r} / \mathrm{min}$ to
$600 \mathrm{r} / \mathrm{min}$.

As shown in Figure 9, the effect curves for cylinders speed on the maize breakage and entrainment loss rates revealed that there was an optimal cylinder speed (350 r/min), on which the maize breakage rate was the lowest $(3.85 \%)$. After the optimal speed, the maize breakage rate increased rapidly with the increase of the cylinder speed. It is because the centrifugal force and the impact force on maize kernels increase rapidly with the cylinder speed increasing. When the cylinder speed was less than the optimal speed, the maize breakage rate increased slightly as the cylinder speed decreased. When the cylinder speed was less than $480 \mathrm{r} / \mathrm{min}$, the maize breakage rate was less than $5 \%$. The entrainment loss rate decreased as the cylinder speed increased. When the cylinder speed increased from $300 \mathrm{r} / \mathrm{min}$ to $400 \mathrm{r} / \mathrm{min}$, the entrainment loss rate decreased obviously. When the cylinder speed was more than $400 \mathrm{r} / \mathrm{min}$, the entrainment loss rate was almost constant. That indicated when the cylinder speed was more than $400 \mathrm{r} / \mathrm{min}$, there was no obvious effect on reducing the maize kernels in bract leaf from the outlet by increasing the cylinder speed, because the ear can be threshed clean when the cylinder speed was more than $400 \mathrm{r} / \mathrm{min}$. When the cylinder speed was less than $400 \mathrm{r} / \mathrm{min}$, as the cylinder speed decreased, the impact force on maize kernels decreased rapidly and the ear cannot be threshed completely, so the entrainment loss rate increased rapidly.

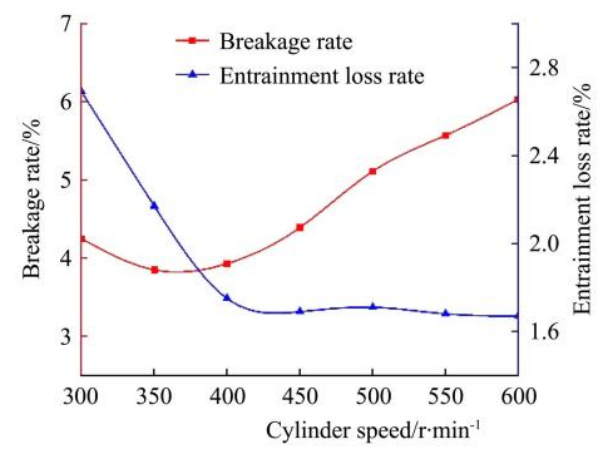

Figure 9 Effects of cylinder speed on evaluation indexes

5.1.2 Effects of concave clearance on the breakage and entrainment loss rates of maize

The following settings were used: cylinder speed of $450 \mathrm{r} / \mathrm{min}$, feeding rate of $10 \mathrm{~kg} / \mathrm{s}$, concave clearance change range of 25 $50 \mathrm{~mm}$.

To study the correlation between concave clearance and maize ear diameter, the experiments were carried out in Fields 1 and 2 (their basic information were shown in Tables 1 and 2). As shown in Figure 10a, being independent of the ear diameter size, as the concave clearance increased, the maize breakage rate decreased gradually. It is because, with the increase of the concave clearance, the extrusion force between the ears in the cylinder is reduced, which results in the decrease of the maize kernel breakage rate. However, at the same concave clearance, the maize breakage rate of the small-diameter maize ears was lower. As shown by the curve in Figure 10b, the entrainment loss rate decreased at first and then increased as the concave clearance increased. Thus, there was an optimal concave clearance, on which the entrainment loss rate was the lowest. The minimum entrainment loss rate correlated with the diameter of the maize ear. The concave clearance on the minimum entrainment loss rate of large-diameter maize ears was larger than that of the small-diameter maize ears. At the same concave clearance, the 
entrainment loss rate was lower for the large-diameter ears. When the concave clearance was larger than the optimal value, the entrainment loss rate increased rapidly with the increase of the concave clearance. It is because, with the increase of the concave clearance, the extrusion force between the ears in the cylinder is reduced, which results in the uncleanness of the maize kernel threshing. When the concave clearance was less than the optimal value, the entrainment loss rate increased slightly as the concave clearance decreased.
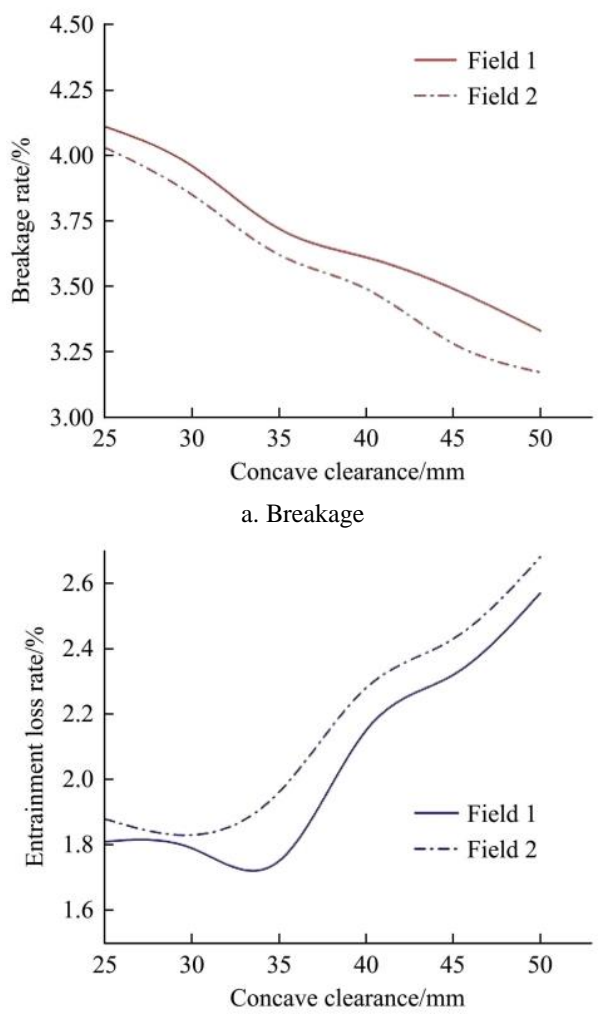

b. Entrainment loss rates

Figure 10 Effects of concave clearance on the maize

5.1.3 Effects of feeding rate on the breakage and entrainment loss rates of maize

In Field 1, the single-factor feeding rate experiment was carried out. The concave clearance was set to $35 \mathrm{~mm}$, the threshing cylinder speed was $450 \mathrm{r} / \mathrm{min}$ and the feed quantities were $8 \mathrm{~kg} / \mathrm{s}, 10 \mathrm{~kg} / \mathrm{s}$ and $12 \mathrm{~kg} / \mathrm{s}$.

The correlation between the maize breakage and entrainment loss rates is shown in Figure 11. The maize breakage rate first decreased and then increased as the feeding rate increased. The threshing process of maize kernels is mainly accomplished by rubbing and squeezing between the ears. When the feeding rate is too small, the impact between the cylinder and the ears increases, which leads to the increase of the breakage rate; When the feeding rate is too large, the extrusion force between the ears is too large, which will also lead to the increase of the breakage rate. Thus, the maize breakage rate was the smallest under the rated feeding rate. However, the maize breakage rate at $12 \mathrm{~kg} / \mathrm{s}$ was slightly lower than that at $8 \mathrm{~kg} / \mathrm{s}$, and the maize breakage rate was $3.72 \%$ when the feeding rate was at the rated value. The entrainment loss rate increased as the feeding rate increased, and the entrainment loss increased obviously when the feeding rate was greater than the rated feeding rate. The results showed that there was a positive correlation between the entrainment loss rate and the extrusion force between the ears of maize.

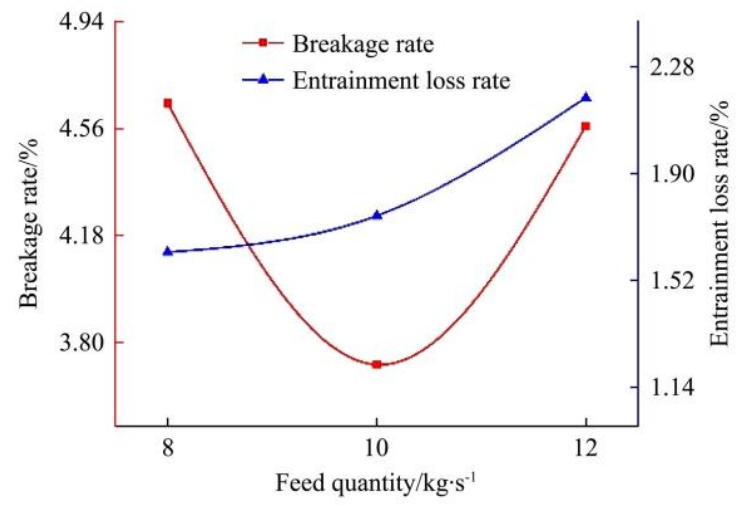

Figure 11 Effects of feeding rate on evaluation indexes

\subsection{Orthogonal experiments}

The Orthogonal experiments were carried out on a single- and double-longitudinal-axial flow maize harvester and designed on the basis of the single-factor experimental results and local harvest experience using maize breakage and entrainment loss rates as evaluation indexes. The orthogonal table $\mathrm{L}_{9}\left(3^{3}\right)$ of Taguchi was used to design the experiment, and cylinder speed, concave clearance and feeding rate were set to three levels as shown in Table 5. The signal-to-noise ratio (SNR) of the results was calculated using the criterion that smaller was better, and the main effect plot of the SNR was analyzed. In Taguchi designs, The SNR is a measure of robustness used to identify control factors by minimizing the effects of uncontrollable factors (noise factors), which means the larger the SNR is, the smaller the noise effects, and the better the parameters set ${ }^{[33]}$. The single- and double-longitudinal-axial flow maize harvesters' orthogonal experiments were carried out in Fields 1 and 3, respectively.

Table 5 Signal factors and levels

\begin{tabular}{ccccc}
\hline Harvester type & Level & Cylinder speed & Concave clearance & Feeding rate \\
\hline \multirow{2}{\text{Single}}{} & 1 & 370 & 35 & 8 \\
longitudinal & 2 & 420 & 40 & 10 \\
\hline & 3 & 470 & 45 & 12 \\
\hline Double & 1 & 500 & 30 & 8 \\
longitudinal & 2 & 550 & 35 & 10 \\
& 3 & 600 & 40 & 12 \\
\hline
\end{tabular}

In the course of the experiment, other harvester parameters were constant, except the cylinder speed, concave clearance and feeding rate. The experiment was repeated three times according to the factor level listed in Table 5. The partial results of the orthogonal experiments are shown in Tables 6-9.

Table 6 Partial experimental results for the single longitudinal axial flow maize harvester

\begin{tabular}{cccccc}
\hline $\begin{array}{c}\text { Experiment } \\
\text { Number }\end{array}$ & $\begin{array}{c}\text { Cylinder } \\
\text { speed }\end{array}$ & $\begin{array}{c}\text { Concave } \\
\text { clearance }\end{array}$ & $\begin{array}{c}\text { Feeding } \\
\text { rate }\end{array}$ & $\begin{array}{c}\text { Broken } \\
\text { rate/\% }\end{array}$ & $\begin{array}{c}\text { Entrainment } \\
\text { loss rate/\% }\end{array}$ \\
\hline 1 & 1 & 1 & 1 & 3.76 & 1.65 \\
2 & 1 & 2 & 2 & 3.05 & 1.36 \\
3 & 1 & 3 & 3 & 3.98 & 1.60 \\
4 & 2 & 1 & 2 & 3.72 & 1.75 \\
5 & 2 & 2 & 3 & 3.79 & 1.89 \\
6 & 2 & 3 & 1 & 4.15 & 1.93 \\
7 & 3 & 1 & 3 & 4.82 & 2.01 \\
8 & 3 & 2 & 1 & 4.48 & 1.86 \\
9 & 3 & 3 & 2 & 4.29 & 1.83 \\
\hline
\end{tabular}


Table 7 Analysis of variance for SNR for the single-longitudinal-axial flow maize harvester

\begin{tabular}{clcccc}
\hline Item & \multicolumn{1}{c}{ Source } & DOF & P & Delta & Rank \\
\hline \multirow{2}{*}{ Broken rate } & Cylinder speed & 2 & 0.017 & 2.05 & 1 \\
$1 \%$ & Concave clearance & 2 & 0.074 & 0.91 & 3 \\
& Feeding rate & 2 & 0.044 & 1.16 & 2 \\
\hline \multirow{2}{*}{ Entrainment } & Cylinder speed & 2 & 0.019 & 1.867 & 1 \\
loss rate/\% & Concave clearance & 2 & 0.064 & 0.561 & 3 \\
& Feeding rate & 2 & 0.067 & 0.965 & 2 \\
\hline
\end{tabular}

Note: DOF is the degree of freedom; $p$-value: $p<0.1$ (significant), $p>0.1$ (insignificant); Delta is the difference between the highest and lowest average response values for each factor.

Table 8 Partial experimental results for the double longitudinal axial flow maize harvester

\begin{tabular}{cccccc}
$\begin{array}{c}\text { Experiment } \\
\text { No }\end{array}$ & $\begin{array}{c}\text { Cylinder } \\
\text { speed }\end{array}$ & $\begin{array}{c}\text { Concave } \\
\text { clearance }\end{array}$ & $\begin{array}{c}\text { Feeding } \\
\text { rate }\end{array}$ & $\begin{array}{c}\text { Broken } \\
\text { rate/\% }\end{array}$ & $\begin{array}{c}\text { Entrainment } \\
\text { loss rate/\% }\end{array}$ \\
\hline 1 & 1 & 1 & 1 & 4.17 & 1.78 \\
2 & 1 & 2 & 2 & 3.65 & 1.58 \\
3 & 1 & 3 & 3 & 4.02 & 1.82 \\
4 & 2 & 1 & 2 & 3.76 & 1.49 \\
5 & 2 & 2 & 3 & 3.66 & 1.65 \\
6 & 2 & 3 & 1 & 3.88 & 1.72 \\
7 & 3 & 1 & 3 & 4.23 & 2.08 \\
8 & 3 & 2 & 1 & 4.12 & 1.91 \\
9 & 3 & 3 & 2 & 3.95 & 1.86 \\
\hline
\end{tabular}

Table 9 Analysis of variance for SNR for the double-longitudinal-axial flow maize harvester

\begin{tabular}{clcccc}
\hline Item & \multicolumn{1}{c}{ Source } & DOF & P & Delta & Rank \\
\hline \multirow{2}{*}{$\begin{array}{c}\text { Broken rate } \\
1 \%\end{array}$} & Cylinder speed & 2 & 0.026 & 0.74 & 1 \\
& Concave clearance & 2 & 0.047 & 0.54 & 3 \\
& Feeding rate & 2 & 0.038 & 0.6 & 2 \\
\hline \multirow{2}{*}{ Entrainment } & Cylinder speed & 2 & 0.007 & 1.616 & 1 \\
loss rate $\%$ & Concave clearance & 2 & 0.078 & 0.453 & 3 \\
& Feeding rate & 2 & 0.017 & 1.028 & 2 \\
\hline
\end{tabular}

Note: DOF is the degree of freedom; $p<0.1$ (significant), $p>0.1$ (insignificant); Delta is the difference between the highest and lowest average response values for each factor.

The $p$ values of the cylinder speed, concave clearance and feeding rate were all less than 0.1 , as shown in Tables 7 and 9. Thus, it was concluded that the three factors of two types of harvester have significant effects on the maize breakage and entrainment loss rates with a confidence of $90 \%$. Using Taguchi parameters regarding rank, the order of the importance of three factors on the maize breakage and entrainment loss rates was cylinder speed, feeding rate, concave clearance.

Figure 12 is the main effects plot of the SNRs for the single (Figures 12a, 12b) and double (Figures 12c, 12d) longitudinal-axial flow maize harvesters. The larger the SNR of the evaluation index, the more likely the factors are to reduce the rates of maize breakage and entrainment loss. For the single-longitudinal-axial flow maize harvester, the rates of maize breakage and entrainment loss were small when the cylinder speed was at level 1. Thus, when the cylinder speed was $370 \mathrm{r} / \mathrm{min}$, the minimum rates of maize breakage and entrainment loss occurred. When the feeding rate was at level 2 , the rates of maize breakage and entrainment loss were small, which indicated that the rates of maize breakage and entrainment loss reached their minimum levels at the rated feeding rate for high-moisture maize. Compared with cylinder speed and feeding rate, the changes in the maize breakage and entrainment loss rates at the three concave clearance levels were not obvious. Thus, the effects of concave clearance on maize breakage and entrainment loss rates were not obvious. Combining with the variance analysis of SNRs, as shown in Table 7, the optimum configuration of the three parameters that resulted in the lowest grain breakage and entrainment loss rates was cylinder speed level 1, concave clearance level 2 and feeding rate level 2 .

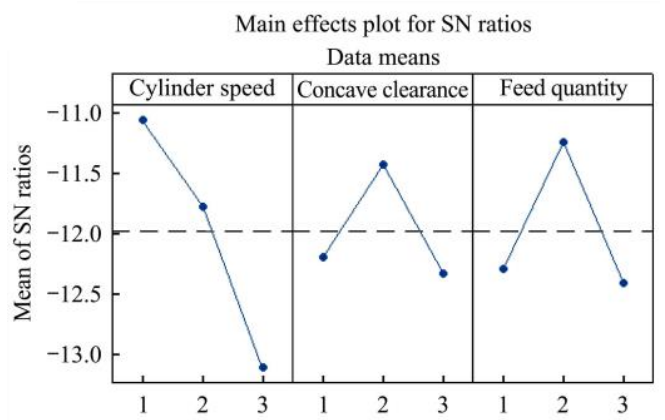

a. $\mathrm{SN}$ ratios of maize breakage for single-longitudinal-axial flow harvester

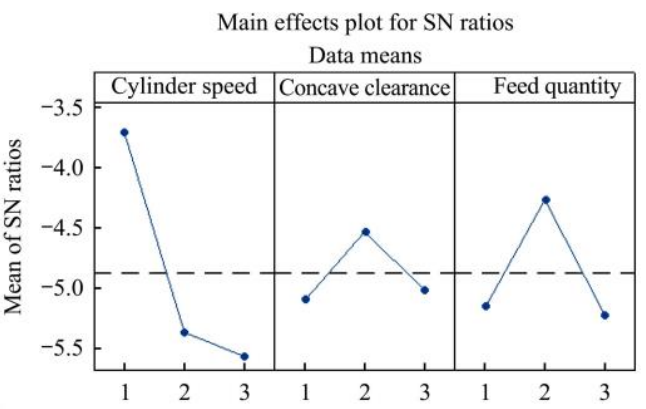

b. $\mathrm{SN}$ ratios of entrainment loss rates for single-longitudinal-axial flow harvester

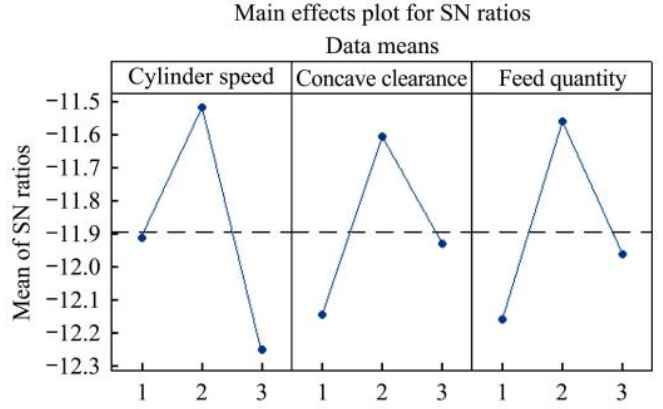

c. SN ratios of maize breakage for double-longitudinal-axial flow harvester

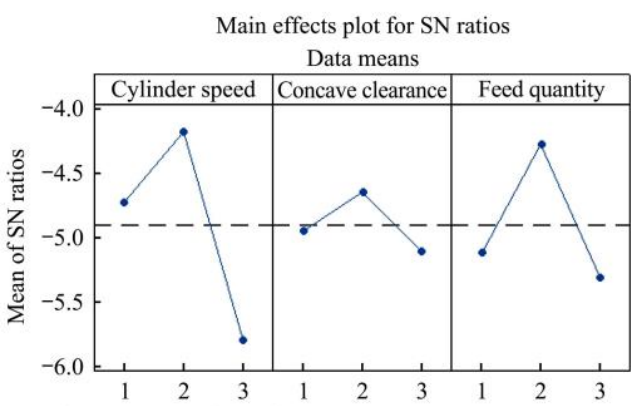

d. SN ratios of entrainment loss rates for double-longitudinal-axial flow harvester

Note: Horizontal axis shows the level of each factor; $\mathrm{SN}$ ratios are the signal-to-noise ratios which is the smaller the better.

Figure 12 Main effect diagrams of signal-to-noise ratios (SNRs)

For the double-longitudinal-axial flow maize harvester, the level 2 cylinder speed resulted in the minimum maize breakage and entrainment loss rates. Thus, for the double-longitudinal-axial flow maize harvester, the optimal cylinder speed was $550 \mathrm{r} / \mathrm{min}$, which was greater than that of the single-longitudinal-axial flow maize harvester. This conclusion is consistent with the smaller diameter of the cylinder of the former compared with that of the latter. The 
smaller cylinder diameter results in a greater linear velocity. The concave clearance could minimize the maize breakage rate at level 2 but the effects on entrainment loss rate were not obvious. The feeding rate could minimize the rates of maize breakage and entrainment loss at level 2. Combining variance analysis of SNRs, as shown in Table 9, the best configuration of the three parameters that resulted in the lowest grain breakage and entrainment loss rates lowest was cylinder speed level 2, concave clearance level 2 and feeding rate level 2 .

\section{Conclusions}

As a result of single-factor and orthogonal experiments, the following conclusions were drawn:

1) For the single-longitudinal-axial flow maize harvester, the maize breakage rate decreased at first and then increased as the cylinder speed increased, while the entrainment loss rate decreased as the cylinder speed increased. When the cylinder speed was over $400 \mathrm{r} / \mathrm{min}$, the entrainment loss rate was almost constant. The minimum value of the maize breakage rate was $3.85 \%$ and the entrainment loss rate was $1.67 \%$ when the cylinder speed was $300-600 \mathrm{r} / \mathrm{min}$.

2) For the single-longitudinal-axial flow maize harvester, the maize breakage rate decreased as the concave clearance increased, while the entrainment loss rate decreased first and then increased as the concave clearance increased. The maize breakage and entrainment loss rates of the large-diameter ears at the same concave clearance level were greater, and the optimum value of the concave clearance was positively correlated with the ear diameter.

3) The maize breakage and entrainment loss rates reached minimum levels at the rated feeding rate; therefore, the rated feeding rate should be maintained during the harvest process to obtain the most efficient production.

4) The orthogonal experiments revealed that the order of the importance of the three factors on the maize breakage and entrainment loss rates was cylinder speed, feeding rate, concave clearance. The optimum threshing parameters for the single-longitudinal-axial flow maize harvester are $370 \mathrm{r} / \mathrm{min}$ cylinder speed, $40 \mathrm{~mm}$ concave clearance and $10 \mathrm{~kg} / \mathrm{s}$ feeding rate. The optimum threshing parameters for the double-longitudinal-axial flow maize harvester are $550 \mathrm{r} / \mathrm{min}$ cylinder speed, $35 \mathrm{~mm}$ concave clearance and $10 \mathrm{~kg} / \mathrm{s}$ feeding rate. The optimal cylinder speed of the double-longitudinal-axial flow maize harvester was greater than that of the single-longitudinal-axial flow maize harvester.

\section{Acknowledgements}

The authors acknowledge that this work was financially supported by the 13th Five-year National Key Research and Development Program (Grant No. 2016YFD0701901).

\section{[References]}

[1] Li S S. Study on the methods of layout optimization design and virtual verification of self-propelled corn harvester. PhD dissertation. Beijing: China Agricultural University, 2016; 139p. (in Chinese)

[2] National Bureau of Statistics of China. Announcement of the national bureau of statistics on food production in 2017. National Bureau of Statistics of China, Department/Division, 2017. (in Chinese)

[3] Geng A J, Yang J N, Zhang J, Zhang Z L, Yang Q Y, Li R X. Influence factor analysis of mechanical damage on corn ear picking. Transactions of the CSAE, 2016; 32(22): 56-62. (in Chinese)

[4] Johnson P C, Clementson C L, Mathanker S K, Grift T E, Hansen A C. Cutting energy characteristics of Miscanthus $x$ giganteus stems with varying oblique angle and cutting speed. Biosyst Eng, 2012; 112(1): 42-48.

[5] Shinners K J, Boettcher G C, Hoffman D S, Munk J T, Muck R E, Weimer P J. Single-pass harvest of corn grain and stover: performance of three harvester configurations. Transactions of the ASABE, 2009; 52(1): 51-60.

[6] Wang J, Li Y, Ma Z, Hu B, Yu S. Structural characteristics and development trend of key equipment of corn harvesting machinery. Journal of Agricultural Mechanization Research, 2019; 41(9): 1-8. (in Chinese)

[7] Yang L, Cui T, Qu Z, Li K, Yin X, Han D, et al. Development and application of mechanized maize harvesters. Int J Agric \& Biol Eng, 2016; 9(3): 15-28.

[8] Colbert T B. Iowa farmers and mechanical corn pickers, 1900-1952. Agricultural History, 2000; 74(2):530-544.

[9] Mahmoud A R, Buchele W F. Corn ear orientation effects on mechanical damage and forces on concave. Transactions of the ASAE, 1975; 18(3): 444-447.

[10] Wacker P. Maize grain damage during harvest. Landtechnik, 2005; 60(2): 84-85.

[11] Irudayaraj J, Haghighi K, Stroshine R L. Finite element analysis of drying with application to cereal grains. Journal of Agricultural Engineering Research, 1992; 53(3): 209-229.

[12] Irudayaraj J, Haghighi K, Stroshine R. Stress analysis of viscoelastic materials during drying. II. Application to grain kernels. Dry Technol, 1993; 11(5): 929-959.

[13] Srivastava A K, Herum F L, Stevens K K. Impact parameters related to physical damage to corn kernel. Transactions of the ASAE, 1976; 19(6): 1147-1151.

[14] Huang H, Faulkner D B, Berger L L, Eckhoff S R. Harvest date influence on dry matter yield and moisture of Corn and stove. Transactions of the ASABE, 2012; 55(2): 593-598.

[15] Chai Z W, Wang K R, Guo Y Q, Xie R Z, Li L L, Ming B, et al. Current status of maize mechanical grain harvesting and its relationship with grain moisture content. Scientia Agricultura Sinica, 2017; 50(11): 2036-2043.

[16] Lei X P. Studies on the feasibility of maize mechanically harvesting grain in Huanghuaihai Regions. Master dissertation. Baoding: Hebei Agriculture University, 2015; 45p. (in Chinese)

[17] Liu J Y, Cui Z K, Ma J C, Jiao W. Problems and countermeasures of wheat corn rotation production mechanization for main crops in Huanghuaihai Region. Journal of Agricultural Mechanization Research, 2016; 38(5): 259-263. (in Chinese)

[18] Gao L X, Li F, Zhang X W, Zhang Y L, Liu X, Jiao W P. Mechanism of moisture content affect on corn seed threshing. Transactions of the CSAM, 2011; 42(12): 92-96. (in Chinese)

[19] Yi K C, Zhu D W, Zhang X W, Yao Z H, Liu Z. Effect of moisture content on corn grain harvesting mechanization. Chinese Agricultural Mechanization, 2016; 37(11): 78-80. (in Chinese)

[20] Qu H J, Zhang D L, Yang T W, Xu Z D. Experimental research on corn threshing performance effected by moisture content. Journal of Agricultural Mechanization Research, 2014; 36(2): 153-156. (in Chinese)

[21] Zhou X. Research the damage mechanism of seed corn and threshing technology with lower damage. Master dissertation. Shenyang: Shenyang Agricultural University, 2006; 7p. (in Chinese)

[22] Petkevichius S, Shpokas L, Kutzbach H D. Investigation of the maize ear threshing process. Biosyst Eng, 2008; 99(4): 532-539.

[23] Xu L Z, Li Y M, Ding L F. Contacting mechanics analysis during impact process between rice and threshing component. Transactions of the CSAE, 2008; 24(6): 146-149. (in Chinese)

[24] Xu L Z, Li Y M, Ma C X, Li H C. Design and experiment of threshing and separating unit with double axial cylinder. Transactions of the CSAM 2009; 40(11): 55-58. (in Chinese)

[25] Qu Z, Zhang D X, Yang L, Zhang T L, Wang Z D, Cui T. Experiment on feed rate and cylinder speed of longitudinal axial flow threshing and separating device for maize. Transactions of the CSAM, 2018; 49(2): 58-65. (in Chinese)

[26] Chinese Academy of Agricultural Mechanization Sciences. Agricultural machinery design manual. China Agricultural Science and Technology Press, 2007; 1885p. (in Chinese)

[27] Di Z F, Cui Z K, Zhang H, Zhou J, Zhang M Y, Bu L X. Design and experiment of rasp bar and nail tooth combined axial flow corn threshing cylinder. Transactions of the CSAE, 2018; 34(1): 28-34. (in Chinese)

[28] Li X P, Gao L X. Performance test on corn thresher with different-speed threshing parts. Transactions of the CSAE, 2009; 25(12): 102-106. (in 


\section{Chinese)}

[29] Keller D L, Converse H H, Hodges T O, Chung D S. Corn kernel damage due to high velocity impact. Transactions of the ASAE, 1972; 15(2): $330-332$

[30] Standardization Administration of the People's Republic of China. Test Methods for Combine Harvester. GB/T21961-2008, 2008; 13p. (in Chinese)

[31] Standardization Administration of the People's Republic of China.
Measuring methods for agricultural machinery testing conditions-General rules. GB/T5262-2008, 2008; 11p. (in Chinese)

[32] Standardization Administration of the People's Republic of China. Thresher-Testing method. GB/T5982-2017, 2017; 16p. (in Chinese)

[33] Support M. What is the signal-to-noise ratio in a Taguchi design? https://support.minitab.com/en-us/minitab/18/help-and-how-to/modeling-st atistics/doe/supporting-topics/taguchi-designs/what-is-the-signal-to-noise-r atio/. Accessed on [2019-08-25]. 